\title{
An Incentive Mechanism to Break the Low-skill Immigration Deadlock*
}

\author{
David de la Croix $^{2} \quad$ Frédéric Docquier ${ }^{3}$
}

April 2010

\begin{abstract}
Although movements of capital, goods and services are growing in importance, workers movements are impeded by restrictive policies in rich countries. Such regulations carry substantial economic costs for developing countries, and prevent global inequality from declining. Even if rich countries are averse to global inequality, a single country lacks incentives to welcome additional migrants as it would bear the costs alone while the benefits accrue to all rich states. Aversion to global inequality confers a public good nature to the South-North migration of low-skill workers. We propose an alternative allocation of labor maximizing global welfare subject to the constraints that the rich countries are at least as well off as in the current "nationalist" (or "Nashionalist") situation. This "no regret" allocation can be decentralized by a tax-subsidy scheme which makes people internalize the fact that as soon as a rich country welcomes an additional migrant, global inequalities are reduced, and each citizen in the rich world is better off too. Our model is calibrated using statistics on immigration, working-age population and output. We simulate the proposed scheme on different sets of rich countries.
\end{abstract}

JEL Classification Codes: F22, F55, D58, D6, D7.

Keywords: Public Good, Inequality Aversion, Immigration policy.

${ }^{*}$ We thank Axel Gosseries and Omer Moav for useful discussions at an early stage of this project. We also thank Georg Kirchsteiger, Caglar Ozden, Maurice Schiff, participants at conferences in Lille (SMYE 2008), Aix en Provence (journées générations imbriquées 2008), CORE-ULG (2009) and at seminars in ETH Zurich and IEM-Nantes for their comments on previous drafts. The authors acknowledge the financial support of the Belgian French speaking community (ARC conventions 09-14019 on "Geographical mobility of factors", and 09-14018 on "Sustainability") and the Belgian Federal Government (Grant PAI P6/07 "Economic Policy and Finance in the Global Economy: Equilibrium Analysis and Social Evaluation."

${ }^{2}$ David de la Croix: IRES and CORE, Université catholique de Louvain, david.delacroix@uclouvain.be

${ }^{3}$ Frédéric Docquier: National Fund for Scientific Research (Belgium) and IRES, Université catholique de Louvain, frederic.docquier@uclouvain.be 


\section{Introduction}

An undeniably stylized fact of the last 50 years is that, with a few exceptions, the poorest countries of the world have not caught up with the industrialized nations in any meaningful way. Although a considerable amount of research has been devoted to understanding the growth and development processes, economists have not yet discovered how to help poor countries take off. For example, the issue of the effectiveness of foreign aid has given rise to many controversial contributions. ${ }^{1}$

Another clue to reducing global poverty is to allow more low-skill workers to migrate from poor to rich countries. As argued in many recent studies, low-skill migration generates huge gains for migrants, their families and, most importantly, the sending countries. By relaxing labor market constraints at origin and inducing large amounts of remittances, low-skill migration should be seen as an explicit component of the development policy of the rich world. In the Global Economic Prospects, the World Bank (2008) reported that international remittances received by developing countries (around 170 billion US dollars in 2005, two thirds of which was sent from developed countries) had doubled since 2000 and were twice as large as official development aid. Records still underestimate the full scale of remittances: unrecorded flows through informal channels may conservatively add 50 percent to official flows. Although the growth impact is unclear, remittances do obviously play an important role in reducing poverty. Migration has other economic implications for poor countries beyond remittances. It raises the demand for low-skill workers at the margin, leading to higher wages, lower unemployment and greater labor force participation. It creates ties between countries, reducing transaction and informational costs. Hence, it is not surprising that development agencies promote migration of the low skilled. For example, the Commitment to Development Index (CDI) computed by the Center for Global Development, an independent American think tank that works to reduce global poverty and inequality, rewards immigration of low-skill people in its index of generosity of advanced countries towards developing countries.

Although movements of capital, goods and services are growing in importance in an increasingly globalized world, workers movements are impeded by highly restrictive and heavily regulated markets for global labor. This is especially true for the low-skill population. In a recent study, Docquier, Lowell, and Marfouk (2009) estimated that low-skill emigrants only represented 1.3 of the low-skill population born in developing countries in 1990 and 2000. This proportion looks small given huge wage differentials observed between high-income and low-income countries.

Although the migration pressure is likely to intensify in the coming decades (given the rising gap in wages between South and North countries and their different demographic futures), migration flows are constrained by immovable anti-immigration sentiments among the citi-

\footnotetext{
${ }^{1}$ Burnside and Dollar (2000) found that the impact of aid on growth was positive in good policy environments (after accounting for the endogeneity of policy and aid). This result has been questioned by Hansen and Tarp (2000) who introduced non-linearities into the aid-growth relationship, and by Easterly, Levine, and Roodman (2003) who used more recent data. In addition, it has been argued that foreign assistance may generate aid dependency relationships in poor countries (see Kanbur 2006).
} 
zens of rich countries. Regulations which restrict migration carry considerable economic costs for developing countries, and prevent global inequality from declining. Clearly, "breaking the gridlock on international labor migration" requires solutions that are politically acceptable in rich countries. In his recent book, Pritchett (2006) advocates several solutions including the greater use of temporary work permits, permit rationing, reliance on bilateral rather than multilateral agreements, and protection of migrants' fundamental human rights. However none of these suggestions seem strong enough to counterbalance the lack of incentives for North citizens to host more low-skill migrants.

This paper uses a political economy model of immigration barriers. The political economy framework is appropriate for explaining immigration restrictions in advanced countries. This was shown by Facchini and Mayda (2008) who analyzed and quantified the role played by economic channels (labor market, welfare state, efficiency gains) on voters' preferences towards immigration. We build on the same idea that citizens' preferences are key ingredients of a political economy model of immigration. However, our purpose is to design an incentivecompatible mechanism that could raise the number of South-North migrants. Our model describes an economy with a set of heterogeneous rich countries and one poor emigration country (representing the group of developing nations). It relies on a minimal set of assumptions. First, physical capital at destination is only owned by citizens who share the surplus income generated by immigrants (which varies with country's total factor productivity). Second, host countries face heterogeneous costs of low-skill immigration; potential reasons for such costs include xenophobic preferences, fear of unemployment, feelings of insecurity and costs of redistribution (in response to price changes or welfare transfers). Third, citizens from all rich countries are averse to global inequality, albeit to a small extent, and internalize that welcoming low-skill migrants from the South reduces extreme poverty.

We model aversion to global inequality using maximin altruistic preferences: the utility of citizens in the rich world depends on their own level of income and the income of the worst off (i.e. low-skill workers living in developing countries). Many behavioral and experimental studies have revealed that individual choices are influenced by social preferences, including altruism, fairness, reciprocity and aversion for inequality (Fehr and Schmidt 2006). The (quasi-) maximin model relates to the ideas presented by Yaari and Bar-Hillel (1984), that players want to help all other players, but are particularly keen to help the person who is worst off. It has been tested by Charness and Rabin $(2002,2005)$. Laboratory experiments reveal that this model does significantly better than altruism or pure self-interest, indicating that there is indeed much concern for those who are getting the lowest payoffs. Fehr and Schmidt (2006) examined the conditions under which the maximin motive plays a role in naturally occurring environments. In a competitive environment, or in an environment where the players view each other as agents behaving strategically, the maximin motive is not likely to be important. However, the maximin motive is highly relevant in the context of charitable giving or in the context of elections with a large number of people, where strategic voting is unlikely to occur. Development assistance, donation to charities and NGOs, or international community's efforts to reach the Millenium Development Goals are evidence of the rich world's concern for extreme poverty. Nevertheless, it should be clear that our model of social preferences is equivalent to a model of self-interest in which improving the situation of the worst-off benefits to the donor (see Andreoni 2006). For example, development objectives 
of the 1970s and 1980s obviously included shoring up support from poor countries in the geopolitics of the cold war. After the fall of the Berlin wall, other targets appeared such as the "war on terror". In the same vein, hosting low-skill legal immigrants might help the rich world reach some of these selfish objectives, e.g. reducing the inflow of illegal migration and refugees.

An important implication of altruism is that all host states receive benefits when any state welcomes poor immigrants. Altruism confers a public good nature to immigration. In other words, poverty reduction is a public good whose financing is subject to a coordination problem. Although households in rich countries suffer from the idea that people in developing countries are really poor, it is not optimal for them to vote for welcoming additional migrants since they bear the cost alone while the benefits accrue to everybody in the world who cares about poverty. We exploit the possible gains underlying this coordination problem.

In a different setting, Rose Skaksen, Malchow-Møller, and Aastrup Jensen (2007) studied the implications of coordinating immigration policies among destination countries. The model contains two types of spill-overs, a terms of trade externality (immigration causes wages and prices to decrease at destination) and a welfare policy externality (fiscal competition to attract immigrants). They show that coordination does not necessarily increase the volume of immigration. It is only the case if the terms of trade externality dominates the welfare policy externality. Based on humanitarian motives, hosting refugees raises the welfare of all potential host-states. Hence, individuals might be expected to obtain some benefit from the knowledge that refugees also find safety in a tier country. On this basis, Hatton (2004) and Hatton and Williamson (2006) argued that EU asylum policy can be viewed as the local provision of public goods, raising the issue of policy coordination across countries. In Bubb, Kremer, and Levine (2007), the main coordination problem comes from the fact that distinguishing refugees and economic migrants (who simply want to raise their wage) is costly. Host countries can then use restrictions (high standard of proof) to deter immigration. This choice exhibits strategic complementarity: "as more states increase their standard of proof, the best response to other states may be to increase the standard of proof." There is a coordination problem there giving rise to multiple equilibria (high or low restrictions for all). The authors see the "1951 Convention Relating to the Status of Refugees" (basically, a convention imposing the "non-refoulement" of refugees) as a Pareto-optimal improving contract that bound states to lower their standard of proof and provide a more efficient level of global public good. Unlike their paper, our model exhibits strategic substitutability: as more states decrease their level of low-skill immigration, the best response of other states is to let more people come in. This excludes the possibility of multiple equilibria, although it does not solve coordination failure. Moreover, none of these studies proceeded to a quantitative assessment of the welfare gain from coordination.

We first construct an allocation of labor in which each rich country decides its immigration level so as to maximize the welfare of its citizens, taking the choices of other countries as given. This Nash equilibrium is labeled as the nationalist (or Nashionalist) allocation. At that allocation, the resulting demand for low-skill immigrants can reasonably be assumed to be lower than the supply. Assuming the nationalist allocation is the observed one, the model can be calibrated using statistics on immigration, working-age population and out- 
put. Based on the calibrated parameters, we consider an alternative allocation which leaves host countries indifferent compared to the nationalist scenario and maximizes the volume of South-North low-skill migration (or equivalently, utility in the South). This allocation is labeled the no-regret allocation. Because there are positive externalities across rich countries when they jointly lower barriers to immigration, it is possible to increase global labor movements without any utility cost for the rich. We then show that the no-regret allocation can be decentralized by a tax-subsidy scheme which makes people internalize the social gains and costs of migration. For different degrees of altruism, we can compute the global rise in low-skill migration and country-specific tax and subsidy rates which allow the no-regret allocation to be decentralized. We simulate the proposed scheme for different sets of rich countries.

The paper is organized as follows. Section 2 presents the theory. The application of the theory using statistics on immigration, working-aged population and output is proposed in Section 3. Section 4 presents our conclusions.

\section{Theory}

In this section, we first describe the framework used to model the attitudes towards lowskill immigrants in rich receiving countries. Second, we study the political economy of South-North migration when each host state maximizes its own welfare function taking the immigration rates of other receiving states as given. This non-cooperative allocation is labeled the nationalist allocation. Third, we model an alternative allocation (labeled the no-regret allocation) in which the number of migrants is maximized subject to a set of implementability constraints. Given the public good nature of migration, it is possible to increase the number of immigrants without welfare losses at destinations. The last subsection investigates how such an allocation can be decentralized with country-specific lumpsum taxes and subsidies per migrant.

\subsection{The Environment}

The world is made of $J+1$ countries, $J$ developed $(j=1 . . J)$ and 1 developing (indexed by 0 ) representing the whole developing world. As the international allocation of labor is determined by the votes of rich countries' citizens, the $J$ developed states are the main actors in the game.

Inside each country, residents are either citizens or migrants. Both groups are homogenous. Every person in the world has preferences defined over its own consumption, $c_{j}$ for citizens and $c_{j}^{m}$ for migrants in country $j$, and over consumption of the poorest $c_{0}$, i.e. those left in the developing world. In addition, citizens' preferences depend on the ratio of migrants to citizens in their country $m_{j} / n_{j}$, while migrants' preferences include a cost of migration. ${ }^{2}$

\footnotetext{
${ }^{2}$ Migrants are likely to be the main beneficiaries of the migration process. But their utility plays no role in our analysis.
} 
Preferences are represented by the following utility function:

$$
U_{j}=u\left(c_{j}\right)+\beta u\left(c_{0}\right)-\gamma_{j} g\left(\frac{m_{j}}{n_{j}}\right) \quad \text { for citizens }
$$

The utility from consumption $u(c)$ is increasing and concave. Individuals are possibly altruistic with respect to the poorest people, i.e. $\beta \geq 0 .{ }^{3}$ The functional form of the first part of the utility, $u\left(c_{j}\right)+\beta u\left(c_{0}\right)$, reflects universal maximin preferences and is accordingly the same across the world. On the other hand, the utility cost of hosting migrants varies across countries, reflecting differences in institutions. In country $j$ it is given by the function $\gamma_{j} g\left(m_{j} / n_{j}\right)$ where $\gamma_{j}>0$ and $g()$ is increasing and convex and satisfies the Inada condition:

$$
\lim _{x \rightarrow \infty} g^{\prime}(x)=+\infty
$$

Potential reasons for such costs include xenophobic preferences, feelings of insecurity, demographic congestion, and the costs of redistribution. Each of these determinants is countryspecific and can also be time-varying. In 1997, a European Union-wide survey revealed that 33 percent of interviewees openly described themselves as "quite racist" or "very racist" 4 The degree of expressed racism varied strongly across countries, peaking at 55 percent in Belgium and amounting to only 14 percent in Luxembourg and Austria. Feelings of insecurity undoubtedly change across years and states; the attacks of September 11, 2001, transformed the landscape of global security and created suspicion toward Arab and Muslim communities, especially in the United States. The fear of unemployment or of a fall in wages depends on the substitutability between citizens and immigrants on the labor market, which is itself affected by the skill composition of the local labor force. Finally, although the net contribution of migrants to welfare transfers does not need to be negative ${ }^{5}$, the generosity of the welfare state affects individual attitudes towards immigrants. Using survey data, Facchini and Mayda (2009) showed that the attitudes of high- and low-skill citizens towards immigration differ and depend on the generosity of welfare benefits, average tax rates and tax progressivity. Notice that the cost is a function of the ratio $m_{j} / n_{j}$ and not $m_{j}$ alone, reflecting the idea that what matters is the proportion of migrants in the total population rather than their absolute number.

In our model, one physical good is produced in each country using labor input $l_{j}$, with technology $\mu_{j} f\left(l_{j}\right)$, with $f$ increasing and concave (this reflects the existence of an unspecified fixed factor). The variable $\mu_{j}$ reflects both the size of the fixed factors and their productivity. $l_{j}$ stands for the quantity of labor used in the economy, including immigrant workers.

\footnotetext{
${ }^{3}$ See e.g. Azam and Laffont (2003) for a similar assumption.

${ }^{4}$ See the Eurobarometer Opinion Poll 47.1 on "Racism and Xenophobia in Europe" presented in Luxembourg in December 1997.

${ }^{5}$ See Auerbach and Oreopoulos (1999) and Bonin, Raffelhüschen, and Walliser (2000) who show that immigration reduces the burden of aging in the United States and Germany. Chojnicki (2006) disaggregated the French net-tax profiles of immigrants by schooling level. He shows that low-skill immigrants exhibited a very modest, albeit positive contribution between the ages of 30 and 50. In the same vein, Boeri, Hanson, and McCormick (2002) confirmed that the contribution of immigrants to the fiscal balance of the welfare state improves with their skills.
} 
Labor input in the poor country is made up of the citizens minus those who emigrate to each of the developed countries. Representing the number of migrants from 0 to $j$ by $m_{j}$, and the $j \times 1$ vector of the $m_{j}$ 's by $\mathbf{m}$, we have

$$
l_{0}=n_{0}-\mathbf{m}^{\prime} \mathbf{1}_{\mathbf{J}}
$$

where $\mathbf{1}_{\mathbf{J}}$ is a column vector of ones of dimension $J$. In developed countries the labor input is given by $l_{j}=n_{j}+m_{j}$. We assume that in equilibrium there is migration from 0 to $j$ only, not from $j$ to $i \in J$, i.e., we disregard migration flows between developed countries.

Definition 1 (Country) A country $j$ is a triplet $\Omega_{j}=\left\{n_{j}, \mu_{j}, \gamma_{j}\right\}$ representing population, technology and preferences towards migrants.

Both local and immigrant workers are paid at their marginal productivity. Locals moreover receive the profits of the country they live in, e.g, because firms or land belong to the citizens. Consumption for a migrant in country $j$ is simply given by the wage rate in $j$ :

$$
c_{j}^{m}=\mu_{j} f^{\prime}\left(n_{j}+m_{j}\right),
$$

and for a citizen in country $j$, it includes wages and profits:

$$
c_{j}=\mu_{j} f^{\prime}\left(n_{j}+m_{j}\right)+\frac{1}{n_{j}}\left[\mu_{j} f\left(n_{j}+m_{j}\right)-\left(n_{j}+m_{j}\right) \mu_{j} f^{\prime}\left(n_{j}+m_{j}\right)\right] .
$$

Income for a worker in the developing country (the so-called left-behind) is equal to his or her average productivity.

$$
c_{0}=\mu_{0} f^{\prime}\left(l_{0}\right)+\frac{1}{l_{0}}\left[\mu_{0} f\left(l_{0}\right)-l_{0} \mu_{0} f^{\prime}\left(l_{0}\right)\right]=\frac{\mu_{0} f\left(l_{0}\right)}{l_{0}}
$$

which is a decreasing function of the quantity of labor $l_{0}$ left in developing countries.

\subsection{Nationalist Allocation}

The population of each potential host country is divided into citizens and migrants. Only citizens have a right to vote and decide what is in their best interest. Remember that it is precisely in the context of elections with a large number of people, where strategic voting is unlikely to occur, that maximin preferences are highly relevant (i.e. voters care about the worst-off).

When voters of a given rich country decide the migration level, they take the actions of other rich countries as given. Hence, the nationalist allocation is a "Nashionalist" equilibrium.

Migrants are paid at their marginal productivity and the profit they generate benefits the citizens. Hence, an increase in immigration will lower the wages of the citizens but will increase their profits. In a classical framework such as ours with two production factors and decreasing marginal returns, the second effect dominates. The positive net increase in 
income of the indigenous population of the host country is the immigration surplus. When citizens vote on immigration, this surplus must be supplemented by the altruistic gain from reducing poverty, and compared with the cost of hosting migrants.

Let us first define the utility of the representative citizen as a function of the migration vector by replacing $c_{j}, c_{0}$ and $l_{0}$ from Equations (3), (4) and (5) in (1):

$$
\begin{aligned}
\varphi_{j}(\mathbf{m})=u\left(\mu_{j} f^{\prime}\left(n_{j}+m_{j}\right)+\frac{1}{n_{j}}\left[\mu_{j} f\left(n_{j}+m_{j}\right)\right.\right. & \left.\left.-\left(n_{j}+m_{j}\right) \mu_{j} f^{\prime}\left(n_{j}+m_{j}\right)\right]\right) \\
& +\beta u\left(\frac{\mu_{0} f\left(n_{0}-\mathbf{m}^{\prime} \mathbf{1}_{\mathbf{J}}\right)}{n_{0}-\mathbf{m}^{\prime} \mathbf{1}_{\mathbf{J}}}\right)-\gamma_{j} g\left(\frac{m_{j}}{n_{j}}\right)
\end{aligned}
$$

The first-order derivative is:

$$
\frac{\partial \varphi_{j}(\mathbf{m})}{\partial m_{j}}=-\frac{m_{j}}{n_{j}} \mu_{j} f^{\prime \prime}\left(n_{j}+m_{j}\right) u^{\prime}\left(c_{j}\right)+\beta \frac{\mu_{0}}{l_{0}}\left(\frac{f\left(l_{0}\right)}{l_{0}}-f^{\prime}\left(l_{0}\right)\right) u^{\prime}\left(c_{0}\right)-\frac{\gamma_{j}}{n_{j}} g^{\prime}\left(\frac{m_{j}}{n_{j}}\right)
$$

Immigration has three effects on the utility of citizens. At the nationalist allocation these three forces balance out at the margin:

- The first term in (7) represents the net increase in citizens' income generated by the marginal migrant. Although increasing the labor force decreases the output per person, it generates a higher income for the citizens since profits accrue to citizens only. This is the immigration surplus. Borjas (1995) provided rough estimates of the immigration surplus for the US. With one type of labor, he arrived at the pessimistic conclusion that a 10 percent increase in the workforce through migration affects citizens' incomes by about 0.1 percent. In a framework with two types of workers, the educational structure of immigration matters. The surplus is a U-shaped function of the proportion of highskill among migrants. In the U.S. case, it amounts to 0.1 percent of income if the proportion of high-skill immigrants equals the proportion of high-skill citizens. It can reach 0.5 percent of citizens' average income if all the immigrants are highly skilled (most of the benefits accrue to low-skill citizens), and 0.36 percent if all immigrants are low skilled (most of the benefits accrue to high-skill citizens). Drinkwater et al. (2007) obtained more optimistic values for the surplus associated with high-skill immigration and conversely more pessimistic values for low-skill when the growth rate is a function of the proportion of high-skill workers in the economy.

- The second term in (7) captures the effect of migration on the average income at origin. Welcoming an additional migrant raises the marginal productivity in the South and improves the well-being of those left behind. If $l_{0}$ is large this effect is likely to be small. For each developed country taken individually this second term plays a minor role in the determination of the migration rate.

- The third term in (7) represents the marginal utility cost of increasing migration.

Let us now define a nationalist allocation: 
Definition 2 A nationalist allocation is a vector $\tilde{\mathbf{m}}$ such that citizens' utility $\varphi_{j}\left(\left[\tilde{m}_{1} . . \tilde{m}_{j-1}\right.\right.$, $\left.\left.m_{j}, \tilde{m}_{j+1} . ., \tilde{m}_{J}\right]^{\prime}\right)$ is maximized with respect to $m_{j}$ in each developed country $j=1 . . J$ given the migration choices of other countries.

Because of condition (2), the migration rate maximizing citizens' utility cannot be infinite. Such a maximizer $\tilde{m}_{j}$ can either be a corner $\left(\tilde{m}_{j}=0\right)$ or an interior solution. If it is an interior solution, it should satisfy: $\partial \varphi_{j}(\mathbf{m}) / \partial m_{j}=0, \partial^{2} \varphi_{j}(\mathbf{m}) / \partial m_{j}^{2}<0$ and $\varphi_{j}\left(\left[m_{1} . . m_{j-1}, \tilde{m}_{j}, m_{j+1} . ., m_{J}\right]^{\prime}\right) \geq \varphi_{j}\left(\left[m_{1} . . m_{j-1}, 0, m_{j+1} . ., m_{J}\right]^{\prime}\right)$ for all $j$.

The following proposition determines the effects of the two important parameters, cost of migration $\gamma_{j}$ and productivity $\mu_{j}$ on the desired migration level $\tilde{m}_{j}$ when it is interior.

Proposition 1 When the nationalist allocation is an interior maximum for country $j$, the immigration level $\tilde{m}_{j}$ is decreasing in $\gamma_{j}$. Moreover, it is increasing in $\mu_{j}$ if and only if the elasticity of marginal utility to consumption is lower than one in absolute value.

Proof: The interior maximum satisfies $\partial \varphi_{j}(\mathbf{m}) / \partial m_{j}=0$ and $\partial^{2} \varphi_{j}(\mathbf{m}) / \partial m_{j}^{2}<0$. The first order condition $\partial \varphi_{j}(\mathbf{m}) / \partial m_{j}=0$ defines an implicit function $\Psi\left(m_{j}, \mu_{j}, \gamma_{j}, n_{j}\right)$. Applying the implicit function theorem, we obtain:

$$
\begin{aligned}
\Psi_{m}^{\prime}\left(m_{j}, \mu_{j}, \gamma_{j}, n_{j}\right) & =\partial^{2} \varphi_{j}(\mathbf{m}) / \partial m_{j}^{2}<0 \\
\Psi_{\gamma}^{\prime}\left(m_{j}, \mu_{j}, \gamma_{j}, n_{j}\right) & =-g^{\prime}\left(m_{j} / n_{j}\right) / n_{j}<0
\end{aligned}
$$

and

$$
\Psi_{\mu}^{\prime}\left(m_{j}, \mu_{j}, \gamma_{j}, n_{j}\right)=-\frac{m_{j}}{n_{j}} f^{\prime \prime}\left(n_{j}+m_{j}\right) u^{\prime}\left(c_{j}\right)\left(1-\sigma_{j}\right)
$$

where

$$
\sigma_{j}=\frac{-c_{j} u^{\prime \prime}\left(c_{j}\right)}{u^{\prime}\left(c_{j}\right)} .
$$

Hence, $d \tilde{m}_{j} / d \gamma_{j}=-\Psi_{\gamma}^{\prime} / \Psi_{m}^{\prime}<0$, and $d \tilde{m}_{j} / d \mu_{j}=-\Psi_{\mu}^{\prime} / \Psi_{m}^{\prime}>0 \Leftrightarrow \sigma_{j}<1$.

The interpretation is the following. First, countries with high $\gamma_{j}$ will unsurprisingly be more reluctant to welcome immigrants. Second, it is not necessarily in the interest of countries with high productivity to welcome relatively more migrants. To understand the proposition let us consider the first term of Equation (7). This term describes the gain in the migration surplus in terms of utility. The effect of $\mu_{j}$ on this term is ambiguous. On the one hand, the larger $\mu_{j}$, the larger is the effect of $m_{j}$ on the surplus. On the other hand, the higher $\mu_{j}$, the bigger is the level of income and the lower is the marginal utility of income. When $\sigma$ is bigger than one, the second effect dominates. In that case, richer countries prefer a low $m_{j} / n_{j}$ ratio and host fewer migrants. Obviously, with the logarithmic utility function, which will be used in the numerical experiment, $\sigma_{j}=1$. 


\section{$2.3 \quad$ No-Regret Allocation}

Under maximin preferences, the nationalist allocation of labor is subject to a coordination failure that leaves all countries worse off than in a coordinated equilibrium. Hence, an international agency maximizing a social welfare function aggregating the utility levels of rich countries' citizens could reach a better allocation. We avoid defining such an arbitrary social welfare function and take advantage of the efficiency gains from coordination to improve the situation of developing countries. In other words, we consider an alternative allocation which leaves host countries indifferent, compared to the nationalist scenario, and maximizes the volume of South-North low-skill migration. If it existed, such an allocation would improve the level of income in developing countries (given equation (5)), improve the utility of new migrants, and leave citizens at destination indifferent. Our no-regret allocation can be defined as following:

Definition 3 A no-regret allocation is a vector $\overline{\mathbf{m}}$ such that $\mathbf{m}^{\prime} \mathbf{1}_{\mathbf{J}}$ is maximized ${ }^{6}$ subject to

$$
\varphi_{j}(\tilde{\mathbf{m}}) \leq \varphi_{j}(\overline{\mathbf{m}}) \quad \text { for } j=1 . . J
$$

Since utility in the South decreases with $l_{0}$, maximizing $\mathbf{m}^{\prime} \mathbf{1}_{\mathbf{J}}$ is identical to maximizing the average utility of residents of developing countries. Inequality (8) is the implementability constraint.

Assuming that the solution $\overline{\mathbf{m}}>0$, and denoting by $\lambda_{j}$ the Lagrange multiplier associated to Constraint (8) in country $j$, the first-order conditions associated with the maximization problem are:

$$
\begin{aligned}
1+\lambda_{j} & \frac{\partial \varphi_{j}(\mathbf{m})}{\partial m_{j}}+\sum_{k \neq j} \lambda_{k} \frac{\partial \varphi_{k}(\mathbf{m})}{\partial m_{j}}=0 \\
& \lambda_{j}\left(\varphi_{j}(\overline{\mathbf{m}})-\varphi_{j}(\tilde{\mathbf{m}})\right)=0, \\
& \lambda_{j} \geq 0 \\
& \varphi_{j}(\overline{\mathbf{m}}) \geq \varphi_{j}(\tilde{\mathbf{m}}) .
\end{aligned}
$$

for $j=1 . . J$, where $\partial \varphi_{j}(\mathbf{m}) / \partial m_{j}$ is given in Equation $(7)$ and $\partial \varphi_{k}(\mathbf{m}) / \partial m_{j}$ is given by

$$
\frac{\partial \varphi_{k}(\mathbf{m})}{\partial m_{j}}=\beta \frac{\mu_{0}}{l_{0}}\left(\frac{f\left(l_{0}\right)}{l_{0}}-f^{\prime}\left(l_{0}\right)\right) u^{\prime}\left(c_{0}\right) .
$$

The summation term in Equation (9) reflects the fact that the externality in now internalized. The derivative $\partial \varphi_{k}(\mathbf{m}) / \partial m_{j}$ is the positive effect on the utility in country $k$ when country $j$ welcomes one additional migrant.

\footnotetext{
${ }^{6}$ Note that $\overline{\mathbf{m}}^{\prime} \mathbf{1}_{\mathbf{J}}<n_{0}$ because of marginal decreasing return to labor.
} 
Considering only situations in which the implementability constraints are binding, i.e. $\lambda_{j}>$ 0 for all $j$, and rearranging Equation (9), leads to the characterization of the no-regret allocation as a set of vectors $\left(\lambda_{j}, \bar{c}_{j}, \bar{m}_{j}\right)$ for $j=1 . . J$ and a pair $\left(\bar{l}_{0}, \bar{c}_{0}\right)$ satisfying:

$$
\begin{aligned}
\frac{1}{\lambda_{j}} & =\frac{\bar{m}_{j}}{n_{j}} \mu_{j} f^{\prime \prime}\left(n_{j}+\bar{m}_{j}\right) u^{\prime}\left(\bar{c}_{j}\right)+\frac{\gamma_{j}}{n_{j}} g^{\prime}\left(\frac{\bar{m}_{j}}{n_{j}}\right)-\beta \frac{\mu_{0}}{\bar{l}_{0}}\left(\frac{f\left(\bar{l}_{0}\right)}{\bar{l}_{0}}-f^{\prime}\left(\bar{l}_{0}\right)\right) u^{\prime}\left(\bar{c}_{0}\right) \sum_{k} \frac{\lambda_{k}}{\lambda_{j}}(10) \\
\bar{c}_{j} & =\mu_{j} f^{\prime}\left(n_{j}+\bar{m}_{j}\right)+\frac{1}{n_{j}}\left[\mu_{j} f\left(n_{j}+\bar{m}_{j}\right)-\left(n_{j}+\bar{m}_{j}\right) \mu_{j} f^{\prime}\left(n_{j}+\bar{m}_{j}\right)\right] \\
0 & =\varphi_{j}(\tilde{\mathbf{m}})-\varphi_{j}(\overline{\mathbf{m}}) \\
\bar{l}_{0} & =n_{0}-\overline{\mathbf{m}}^{\prime} \mathbf{1}_{\mathbf{J}} \\
\bar{c}_{0} & =\mu_{0} f\left(\bar{l}_{0}\right) / \bar{l}_{0} .
\end{aligned}
$$

When there is no altruism, $\partial \varphi_{k}(\mathbf{m}) / \partial m_{j}$ equals zero in Equation (9) and the public good nature of South-North migration vanishes. There is no coordination failure and it is impossible to improve the situation of developing countries without reducing welfare in the rich world. Without altruism, the no-regret allocation is identical to the nationalist allocation. With altruism, Equation (9) implies that the coordinated value for $\partial \varphi_{j}(\mathbf{m}) / \partial m_{j}$ becomes negative, i.e. each rich country goes beyond its nationalist equilibrium (in which $\partial \varphi_{j}(\mathbf{m}) / \partial m_{j}$ equals zero). The set of implementability constraints (8) determines the extent to which immigration can be increased. This yields the following propositions:

Proposition 2 In the absence of altruism, the no-regret allocation coincides with the nationalist allocation, i.e.

$$
\beta=0 \Rightarrow \overline{\mathbf{m}}=\tilde{\mathbf{m}}
$$

Proof: For country $j, \varphi_{j}(\overline{\mathbf{m}})=\varphi_{j}(\tilde{\mathbf{m}})$. If $\beta=0, \varphi_{j}$ depends on $m_{j}$ but not on the other elements of the vector $\mathbf{m}$. We can then write $\varphi_{j}\left(\bar{m}_{j}\right)=\varphi_{j}\left(\tilde{m}_{j}\right)$. Since, at $\tilde{m}_{j}, \varphi_{j}$ is maximized, $\bar{m}_{j}=\tilde{m}_{j}$.

Proposition 3 Assume all rich countries are similar, i.e. $\mu_{j}=\mu, \gamma_{j}=\gamma$ and $n_{j}=n$ for all $j \in[1, J]$, and $\beta>0$. Then the symmetric allocations $\tilde{m}$ and $\bar{m}$ satisfy $\bar{m}>\tilde{m}$.

Proof: With symmetric countries and allocations, the system of equalities $\varphi_{j}(\tilde{\mathbf{m}})=\varphi_{j}(\overline{\mathbf{m}})$ reduces to $\varphi_{j}(\tilde{m})=\varphi_{j}(\bar{m})$, where $\tilde{m}$ and $\bar{m}$ are scalars. For $\beta>0$, we know that $\varphi_{j}^{\prime}(\tilde{m})>0$ thanks to the positive externality. We also know that $\varphi_{j}(+\infty)=-\infty$ because of the convex cost of welcoming migrants. $\varphi_{j}()$ is continuous, increases after point $\tilde{m}$, and then decreases and tends to $-\infty$ as $m$ gets large. Thus $\bar{m}$ exists such that $\bar{m}>\tilde{m}$ and $\varphi_{j}(\bar{m})=\varphi_{j}(\tilde{m})$.

Proposition 4 Assume $\beta$ is strictly positive and close to zero. Then, $\forall j: \bar{m}_{j}>\tilde{m}_{j}$. 
Proof: We first decompose the utility function $\varphi_{j}$ given in (6) into two components:

$$
\varphi_{j}(\mathbf{m})=\hat{\varphi}_{j}\left(m_{j}\right)+\breve{\varphi}(\mathbf{m}) .
$$

$\breve{\varphi}(\mathbf{m})$ includes the altruistic part (which is the same for all countries $j$ ). The implementability constraint (12) is rewritten as:

$$
\forall j: \hat{\varphi}_{j}\left(\bar{m}_{j}\right)+\breve{\varphi}(\overline{\mathbf{m}})=\hat{\varphi}_{j}\left(\tilde{m}_{j}\right)+\breve{\varphi}(\tilde{\mathbf{m}}) .
$$

Assume $\beta$ is small. Since $\overline{\mathbf{m}}=\tilde{\mathbf{m}}$ for $\beta=0$ (Proposition 2), $\overline{\mathbf{m}}$ should be close to $\tilde{\mathbf{m}}$ for $\beta$ small, by continuity. We accordingly take a second order approximation of $\tilde{\varphi}_{j}\left(\bar{m}_{j}\right)$ around $\tilde{m}_{j}$ :

$$
\hat{\varphi}_{j}\left(\bar{m}_{j}\right) \approx \hat{\varphi}_{j}\left(\tilde{m}_{j}\right)+\hat{\varphi}_{j}^{\prime}\left(\tilde{m}_{j}\right)\left(\bar{m}_{j}-\tilde{m}_{j}\right)+\frac{1}{2} \hat{\varphi}_{j}^{\prime \prime}\left(\tilde{m}_{j}\right)\left(\bar{m}_{j}-\tilde{m}_{j}\right)^{2} .
$$

Because $\tilde{m}_{j}$ is close to the maximum of the function $\hat{\varphi}_{j}\left(\tilde{m}_{j}\right)$ (or exactly the maximum if the relative size of the country is zero), we see that $\hat{\varphi}_{j}^{\prime}\left(\tilde{m}_{j}\right) \approx 0$ and $\hat{\varphi}_{j}^{\prime \prime}\left(\tilde{m}_{j}\right)<0$. We next take a first-order approximation of $\breve{\varphi}(\overline{\mathbf{m}})$ around $\tilde{\mathbf{m}}$ :

$$
\breve{\varphi}(\overline{\mathbf{m}}) \approx \breve{\varphi}(\tilde{\mathbf{m}})+\left[\partial \breve{\varphi} / \partial \tilde{m}_{j}\right]^{\prime}(\overline{\mathbf{m}}-\tilde{\mathbf{m}}) .
$$

where $\left[\partial \breve{\varphi} / \partial \tilde{m}_{j}\right]$ is a vector of the first-order derivatives of $\breve{\varphi}$ with respect to $m_{j}$. Replacing the two approximations in the implementability constraint, and simplifying, leads to:

$$
\forall j: \hat{\varphi}_{j}^{\prime \prime}\left(\tilde{m}_{j}\right)\left(\bar{m}_{j}-\tilde{m}_{j}\right)^{2}+\left[\partial \breve{\varphi} / \partial \tilde{m}_{j}\right]^{\prime}(\overline{\mathbf{m}}-\tilde{\mathbf{m}}) \approx 0 .
$$

We can write $\left(\bar{m}_{j}-\tilde{m}_{j}\right)^{2}=\left(\bar{m}_{j}-\tilde{m}_{j}\right) V_{j}^{\prime}(\overline{\mathbf{m}}-\tilde{\mathbf{m}})$ where $V_{j}$ is a vector of zeros with a one at position $j$. Replacing this expression and simplifying leads to:

$$
\forall j: \hat{\varphi}_{j}^{\prime \prime}\left(\tilde{m}_{j}\right)\left(\bar{m}_{j}-\tilde{m}_{j}\right) V_{j}^{\prime}+\left[\partial \breve{\varphi} / \partial \tilde{m}_{j}\right]^{\prime} \mathbf{1}_{\mathbf{J}} \approx 0 .
$$

Solving for $\bar{m}_{j}$ leads to

$$
\forall j: \bar{m}_{j}=\tilde{m}_{j}-\frac{\left[\partial \breve{\varphi} / \partial \tilde{m}_{j}\right]^{\prime} \mathbf{1}_{\mathbf{J}}}{\varphi_{j}^{\prime \prime}\left(\tilde{m}_{j}\right)} .
$$

Since all the derivatives $\partial \breve{\varphi} / \partial \tilde{m}_{j}$ are positive (externality) and $\varphi_{j}^{\prime \prime}\left(\tilde{m}_{j}\right)<0$, we have $\forall j$ : $\bar{m}_{j}>\tilde{m}_{j}$.

\subsection{The Decentralization Scheme}

Our decentralization scheme requires a group of rich countries to agree to put a significant amount of money into a global migration fund and to delegate the responsibility of managing it to an international agency. This agency would have a constitution setting out how money will be paid out according to changes in immigration from developing countries. As in Gersbach and Winkler (2007)'s global refunding system to cope with CO2 emissions, no further coordination is required, except in administering the system, measuring labor flows and distributing money. Such a system does not need additional enforcement mechanisms. 
Rich countries will choose to accept more migrants on their own, and they will not have incentives to leave the system.

More precisely, the set of developed countries will establish a migration agency to organize the tools needed to decentralize the cooperative solution. Each country would pay a lump sum tax to the agency. The vector of lump-sum taxes is denoted by q. Each country would also enjoy a subsidy per additional migrant it welcomed. The subsidy rates are countryspecific and their vector is $\mathbf{p}$. In other words, each country is allowed to avoid paying the lump-sum tax $q_{j}$ by welcoming immigrants and getting a subsidy $p_{j}$ for each of them. The global migration fund would only involve migrants originating from developing countries. Those immigrants would get a visa only allowing them to reside in host country $j$, not to move from $j$ to another participating country. Hence, the decentralization problem of the agency is to define the appropriate set of taxes and subsidies such that each country $j$ agrees to host the optimal number of immigrants $\tilde{m}_{j}$, and such that the agency's global budget constraint is balanced:

$$
\overline{\mathbf{p}}^{\prime} \mathbf{m}-\overline{\mathbf{q}}^{\prime} \mathbf{1}_{\mathbf{J}}=0 .
$$

This decentralization problem can be written as follows:

Proposition $\mathbf{5}$ The no-regret allocation $\overline{\mathbf{m}}$ can be decentralized with subsidy rates $\overline{\mathbf{p}}$ and lump-sum taxes $\overline{\mathbf{q}}$ satisfying $\bar{p}_{j} \bar{m}_{j}=\bar{q}_{j} \forall j$, and

$$
\frac{\bar{p}_{j}}{n_{j}} u^{\prime}\left(\bar{c}_{j}\right)-\beta \frac{\mu_{0}}{\bar{l}_{0}}\left(\frac{f\left(\bar{l}_{0}\right)}{\bar{l}_{0}}-f_{0}^{\prime}\left(\bar{l}_{0}\right)\right) u^{\prime}\left(\bar{c}_{0}\right)\left[\sum_{k \neq j} \frac{\lambda_{k}}{\lambda_{j}}\right]=\frac{1}{\lambda_{j}} \quad \text { for } j=1 . . J .
$$

where the multipliers $\lambda$ 's are solution to Equations (9).

Proof: Introducing the subsidy scheme, the objective of an individual country becomes

$$
\begin{aligned}
\hat{\varphi}_{j}\left(\mathbf{m}, p_{j}, q_{j}\right)=u\left(\mu_{j} f^{\prime}\left(n_{j}+m_{j}\right)\right. & +\frac{1}{n_{j}}\left[\mu_{j} f\left(n_{j}+m_{j}\right)-\left(n_{j}+m_{j}\right) \mu_{j} f^{\prime}\left(n_{j}+m_{j}\right)\right] \\
& \left.+\frac{1}{n_{j}}\left[p_{j} m_{j}-q_{j}\right]\right)+\beta u\left(\frac{\mu_{0} f\left(n_{0}-\mathbf{m}^{\prime} \mathbf{1}_{\mathbf{J}}\right)}{n_{0}-\mathbf{m}^{\prime} \mathbf{1}_{\mathbf{J}}}\right)-\gamma_{j} g\left(\frac{m_{j}}{n_{j}}\right),
\end{aligned}
$$

with $\hat{\varphi}_{j}(\mathbf{m}, 0,0)=\varphi_{j}(\mathbf{m})$. The first order condition for an interior maximum is:

$$
\left(\frac{p_{j}}{n_{j}}-\frac{m_{j}}{n_{j}} \mu_{j} f^{\prime \prime}\left(n_{j}+m_{j}\right)\right) u^{\prime}\left(c_{j}\right)+\beta \frac{\mu_{0}}{l_{0}}\left(\frac{f\left(l_{0}\right)}{l_{0}}-f^{\prime}\left(l_{0}\right)\right) u^{\prime}\left(c_{0}\right)-\frac{\gamma_{j}}{n_{j}} g^{\prime}\left(\frac{m_{j}}{n_{j}}\right)=0 .
$$

Replacing $m_{j}$ by $\bar{m}_{j}$ (and the corresponding $\bar{l}_{0}, \bar{c}_{j}$ and $\bar{c}_{0}$ from Equations (11)-(13)) and using Equation (10) we obtain Equation (16). This condition determines the subsidy rate such that each country will choose the no-regret level of migration. In addition, we also need to satisfy the implementability constraint (12). Doing so requires $\bar{q}_{j}=\bar{m}_{j} / p_{j}$, as $\hat{\varphi}_{j}\left(\overline{\mathbf{m}}, p_{j}, \bar{m}_{j} / p_{j}\right)=\varphi_{j}(\overline{\mathbf{m}})=\varphi_{j}(\tilde{\mathbf{m}})$. As we have $\bar{p}_{j} \bar{m}_{j}=\bar{q}_{j} \forall j$, the global budget constraint (15) is automatically satisfied.

Our problem is not the same as the usual one in the environmental literature where a planner targets a global level of pollution and decentralizes the optimal policy either through a tax on 
pollutants or through tradable quotas. In our case, the fact that we take the implementability constraints (12) explicitly into account prevents the decentralization of the policy through a uniform subsidy scheme. Indeed, Proposition 5 shows that, in the case of asymmetric host countries, it is not possible to decentralize the no-regret allocation with a uniform subsidy $p$ (or alternatively with a system of tradable immigration duties in which each country would sell/buy migrants at a market price $p$ ). The constraints (12) require the use of additional instruments, such as the differentiated subsidy rates $p_{j}$.

The same implementability constraint explains why there are no monetary transfers between countries at the no-regret solution. Compared to the nationalist allocation, Equation (12) implies that citizens enjoy the same level of utility by bearing more domestic immigration costs and benefiting from lower global poverty. In a command optimum, a benevolent planner could reach this solution by imposing a larger number of migrants on each host country, with no need to transfer money between them. Hence, in a market context, we distort immigration decisions by subsidizing immigrants, but we need to avoid additional income effects. This can be done by levying a lump-sum tax on destination countries and allowing them to retrieve the amount paid to the global fund by hosting more migrants.

\section{Quantitative Assessment}

Assuming that developed countries initially conduct nationalist policies, the goal of this section is to simulate the impact of a no-regret treaty on the immigration stock. Our model is static and we consider that the initial nationalist allocation of labor is the allocation observed in 2000. The outcome of our treaty depends on the number of countries involved, as well as their size, income level and aversion towards immigration. The size is here measured by the number of citizens, $n_{j}$. The income level is determined by the level of total factor productivity, $\mu_{j}$. The anti-immigration sentiments of citizens are proxied by the parameter $\gamma_{j}$ which thus reflects concerns about redistribution, the provision of public goods, security risks and cultural blending.

\subsection{Data}

The aggregate developing country $(j=0)$ includes all low and middle-income countries as defined in the World Bank classification. ${ }^{7}$ For the $J$ developed countries we considered three different possibilities: the G7 countries (Canada, France, Germany, Italy, Japan, the United Kingdom and the United States), the high-income countries members of the OECD (Organization for Economic Co-operation and Development), and a set of 42 high-income countries (following the World Bank classification but excluding countries with populations of less than 250,000).

Data for $n_{j}+m_{j}$ were obtained from the United Nations Population Division database (working-age population). ${ }^{8}$ Data on $m_{j}$ (the number of working-age immigrants from de-

\footnotetext{
${ }^{7}$ Available from www.worldbank.org/data/.../classgroups.htm.

${ }^{8}$ Available from www.un.org/esa/population.
} 
veloping countries) were obtained from Parsons et al. (2007). They provide a $226 \times 226$ matrix of origin-destination stocks by country. The data are generated by disaggregating the information on migrant stock in each destination country or economy as given in its census. The reference period is the 2000 round of population censuses. The data set provides stocks of migrants, not flows. Four versions of the database are available, at increasing levels of completeness, but decreasing levels of accuracy as the missing data are added via assumptions and interpolation with each successive version. We use the most comprehensive bilateral matrix (version 4). This allows us to identify immigrants originating from developing countries. Since the database does not provide information on the number who are of working-age, we assume that the proportion of working-aged migrants is the same as that of citizens. In addition, the data set does not distinguish low-skill and high-skill migrants. We assumed that the majority of South-North migrants are low skilled. Combining UN data with Parsons' database, we derived the statistics for $n_{j}$ and $m_{j} / n_{j}$. Table 1 gives a selection of these statistics. It is worth noting that the ratio $m_{j} / n_{j}$ exceeded one in Qatar (2.371) and the United Arab Emirates (1.697). It exceeded 50 percent in Kuwait (0.670), Hong Kong (0.602) and Bahrain (0.549). However, the ratio was particularly low in Korea (0.002), Malta (0.003) and Japan (0.005).

Table 1: Data on the number of citizens and immigrants in selected countries

\begin{tabular}{lcc}
\hline \hline & $n_{j}(\times 1000)$ & $m_{j} / n_{j}$ \\
\hline Developing $(j=0)$ & $2,490,589$ & \\
France & 37,451 & 0.079 \\
Germany & 55,516 & 0.086 \\
Japan & 91,839 & 0.005 \\
Korea Rep & 42,217 & 0.002 \\
Qatar & 104 & 2.371 \\
UK & 38,515 & 0.048 \\
USA & 167,564 & 0.095 \\
\hline \hline
\end{tabular}

Data on GDP in purchasing power parity in 2000 were obtained from the World Development Indicators (World Bank, 2008).

\subsection{Calibration}

We now select specific functional forms and assign values to the parameters in order to match a series of targets. Table 2 summarizes the various parameters and the paragraphs below describe the calibration method.

The gross domestic product is given by the Cobb-Douglas production function:

$$
\mu_{j} l_{j}^{\alpha} \quad \text { where } \mu_{j}=\hat{\mu}_{j} n_{j}^{1-\alpha} \text {. }
$$

The explicit inclusion of $n_{j}^{1-\alpha}$ captures the fact that the quantity of other potential fixed factors (such as land or physical capital) is proportional to the number of citizens. Using 
the production function, we calibrate the parameters $\hat{\mu}_{j}$ to match cross-country differences in GDP in the developed world. $\hat{\mu}_{j}$ reflects total factor productivity and, as we will see in Figure 1, is independent of the size of the country.

The utility function $u($.$) is logarithmic. This choice is comforted by the fact that there is no$ significant correlation between productivity and observed immigration rates, a result which is obtained when the elasticity of marginal utility to consumption is 1 (see Proposition 1).

Using the chosen utility and production functions for the analysis of the nationalist allocation (Section 2.2), it can be shown that the migrants share of the population, $\tilde{m}_{j} / n_{j}$, is independent of the size of the local population $n_{j}$ if and only if $\beta=0$. In the absence of altruism $(\beta=0)$, the first order derivative (7) depends on $m_{j}$ and $n_{j}$ only through the ratio $m_{j} / n_{j}$. When there is some altruism $(\beta>0)$, the size of the country affects its capacity to improve the situation of the worst off, and $m_{j} / n_{j}$ will be affected by the country size $n_{j}$. However, for low values of $\beta$, this effect is hardly perceptible (a property verified by the data).

The cost of immigration is given by the quadratic function $\gamma_{j}\left(m_{j} / n_{j}\right)^{2} / 2$. To identify $\gamma_{j}$ from Equation (7), we need to calibrate the altruism factor $\beta$. We know from the literature that, in multi-person dictator games, many subjects care about the worst-off player's payoff. Hence, $\beta$ is likely to be positive. Unfortunately, the literature does not contain a value for this parameter that we can readily apply to our context. Charness and Rabin $(2002,2005)$ though, provide estimates for a parameter $\rho$ which is related to our $\beta$. They assume that the "social" utility function for players's B is $\rho r x_{A}+(1-\rho r) x_{B}$, where $x_{A}$ is the pay-off of player $\mathrm{A}, x_{B}$ is the payoff of player $\mathrm{B}, r=1$ if $x_{B}>x_{A}$, and $r=0$ otherwise. In this context, the marginal rate of substitution between the payoff of the rich and that of the poor is: $-\rho /(1-\rho)$. While in our model, the marginal rate of substitution between the rich household's consumption and that of the developing country's households is: $-\beta u^{\prime}\left(c_{0}\right) / u^{\prime}\left(c_{j}\right)$. The parameter $\rho$ which best reproduces the data from from Charness and Rabin (2005) dictator games is 0.344. (Considering dictator games only avoids possible confounds with reciprocity considerations) We can then set $\beta$ by equalizing the two marginal rates of substitution:

$$
\frac{\rho}{1-\rho}=\frac{\beta u^{\prime}\left(c_{0}\right)}{u^{\prime}\left(c_{j}\right)}
$$

Table 2: Calibrated parameters

\begin{tabular}{lcc}
\hline \hline Parameter & Value & Target \\
\hline$\alpha$ & $2 / 3$ & observed labor income share \\
$\beta_{\max }$ & 0.07 & experimental evidence from Charness and Rabin $(2005)$ \\
$\beta$ & $\in\left(0, \beta_{\max }\right)$ & \\
$\beta_{0}$ & 0.007 & benchmark value \\
$\mu_{j}$ & see Fig. 1 & observed GDP per worker (PPP) \\
$\gamma_{j}$ & see Fig. 1 & $\tilde{m}_{j}=$ observed migration stock \\
\hline \hline
\end{tabular}


Using US data for $c_{j}$ leads to $\beta=0.07$. We consider this rather large number as an upper bound for the true parameter $\beta$ and denote it by $\beta_{\max }$. Indeed, while the basic motives such as aversion for inequality or altruism seem to be quite robust, the exact functional form of the models and the parameters used in this literature are not - they vary with the game played, the subjects used in the experiments, etc. For example, Bekkers (2007) displays a more pessimistic view of altruism. Respondents to a survey had to decide whether to donate what they earned by participating in the survey. The money offered by respondents benefitted charities (so it measured altruism with respect to the distant poor). Only $5.7 \%$ of the participants donated. It is not possible however to infer a value for our preference parameter $\beta$ based on this survey, since the game never allowed the reward to be split between oneself and the recipient.

A simple numerical example allows us to show that $\beta_{\max }$ is too high. Using our logarithmic utility function and disregarding migration, let us introduce the possibility of a monetary transfer from a rich country with income per capita at US\$40,000 (i.e. approximately the US level) to a poor country with income per capita at US\$250 (i.e. the level observed in the 20 poorest countries of the world). Assuming identical sizes, the optimal transfer from the perspective of the rich country would amount to about US $\$ 2,500$, i.e. ten times the level of pre-transfer income of the poor country. The World Development Indicators reveal that official aid to the poorest countries only represents 12.2 percent of their GDP. Such an amount can be obtained by using $\beta_{0}=0.007=\beta_{\max } / 10$. Consequently, we will use $\beta_{0}$ as the benchmark value, but provide simulation results for all values of $\beta$ comprised between zero and $\beta_{\max }$.

Based on the nationalist optimal migration policy defined in Definition 2 (see eq (7)) we calibrated the $\gamma_{j}$ to match the observed immigration stocks in developed countries. Since all countries have a positive level of immigration, the possibility of corner solutions is ruled out. In the high-income country group, the calibrated $\gamma_{j}$ ranged from 0.018 (Qatar) to 0.122 (South Korea). Figure 1 shows the calibrated $\left\{\mu_{j}, \gamma_{j}\right\}$ for each country. There is no sign of correlation between productivity and aversion towards emigration.

\subsection{No-regret allocation (with $\beta_{0}$ )}

Assuming that $\beta$ takes its benchmark value $\beta_{0}$, we next computed the corresponding noregret allocation. This basically amounts to solving the system

$$
\varphi_{j}(\tilde{\mathbf{m}})=\varphi_{j}(\overline{\mathbf{m}})
$$

where the vector $\tilde{\mathbf{m}}$ is equal to the vector of observed migration levels. In our numerical experiments, we consider three alternative sets of participating countries, as mentioned above. Table 3 displays the allocations obtained for each host country.

Table 4 provides some summary statistics. The additional migration made possible by the no-regret allocation ranges from 12.8 to 24.4 million working age migrants depending on the set of countries considered. These numbers are rather large compared to the 42.5 million migrants originating from developing countries and living in high-income countries today $(+44,+66$ and +57 percent respectively for the three sets considered). This shows that, 
Table 3: Migration stocks in different allocations and sets of participating countries

\begin{tabular}{|c|c|c|c|c|}
\hline \multirow[t]{2}{*}{ Country } & \multirow[t]{2}{*}{ Nationalist } & \multicolumn{3}{|c|}{ No-regret $\left(\beta_{0}\right)$} \\
\hline & & G7 & OECD & High income \\
\hline Australia & 1011 & & 1467 & 1477 \\
\hline Austria & 536 & & 737 & 742 \\
\hline Bahamas & 12 & & & 18 \\
\hline Bahrain & 129 & & & 135 \\
\hline Belgium & 351 & & 664 & 671 \\
\hline Brunei & 50 & & & 53 \\
\hline Canada & 2109 & 2626 & 2796 & 2812 \\
\hline Cyprus & 16 & & & 39 \\
\hline Denmark & 148 & & 320 & 323 \\
\hline Finland & 56 & & 249 & 252 \\
\hline France & 2967 & 4085 & 4452 & 4486 \\
\hline Germany & 4753 & 6338 & 6874 & 6925 \\
\hline Greece & 624 & & 907 & 914 \\
\hline Hong Kong & 1764 & & & 1843 \\
\hline Iceland & 5 & & 13 & 13 \\
\hline Ireland & 45 & & 166 & 169 \\
\hline Israel & 949 & & & 1015 \\
\hline Italy & 915 & 2497 & 2962 & 3005 \\
\hline Japan & 498 & 3152 & 4059 & 4144 \\
\hline Korea Rep & 72 & & 1613 & 1649 \\
\hline Kuwait & 524 & & & 545 \\
\hline Luxembourg & 18 & & 30 & 31 \\
\hline Macao & 15 & & & 27 \\
\hline Malta & 1 & & & 16 \\
\hline Netherlands & 774 & & 1201 & 1211 \\
\hline New Zealand & 125 & & 227 & 229 \\
\hline Norway & 123 & & 262 & 265 \\
\hline Portugal & 308 & & 612 & 619 \\
\hline Qatar & 247 & & & 250 \\
\hline Saudi Arabia & 2111 & & & 2327 \\
\hline Singapore & 363 & & & 442 \\
\hline Slovenia & 34 & & & 106 \\
\hline Spain & 1018 & & 2329 & 2357 \\
\hline Sweden & 410 & & 655 & 660 \\
\hline Switzerland & 525 & & 700 & 704 \\
\hline UAE & 1047 & & & 1065 \\
\hline UK & 1838 & 3138 & 3544 & 3582 \\
\hline USA & 16000 & 2054 & 21628 & 21777 \\
\hline
\end{tabular}


Figure 1: Calibrated $\hat{\mu}_{j}$ (productivity) and $\gamma_{j}$ (aversion for migration)

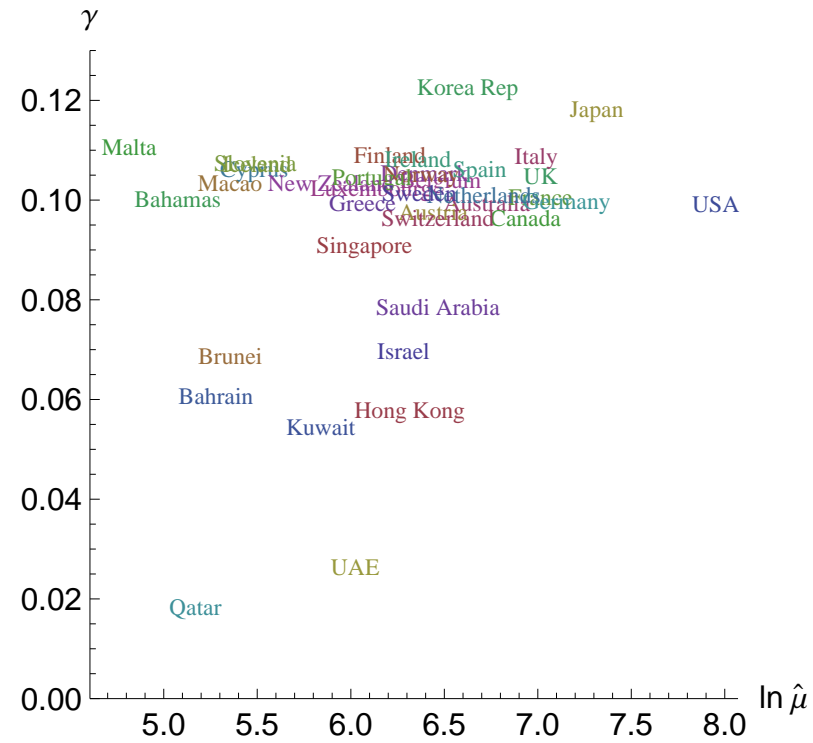

with a reasonable altruism, the public-good externality of migration policy is very significant. The sensitivity of the results to altruism is analyzed in a subsequent section. The change in immigration rates is mostly increasing with $\gamma_{j}$. On average, the no-regret allocation requires countries with high $\gamma_{j}$ and low nationalist immigration rates to host more migrants. In these countries (e.g. Korea, Japan), the marginal cost of hosting migrants is lower given the convex form of $g\left(m_{j} / n_{j}\right)$.

We also computed the effect of such large migration flows on the ratio between US GDP and the average GDP in developing countries. This ratio is reduced from 7.07 to 6.98 in the most favorable case where all high-income countries participate in the scheme.

Table 4: Total additional working age migration $(\times 1000)$ and ratio of US GDP to developing world GDP under the various scenarios

\begin{tabular}{|c|c|c|c|c|}
\hline & \multirow[t]{2}{*}{ Nationalist } & \multicolumn{3}{|c|}{ No-regret $\left(\beta_{0}\right)$} \\
\hline & & G7 & OECD & High income \\
\hline$\overline{\mathbf{m}}^{\prime} \mathbf{1}_{\mathbf{J}}-\tilde{\mathbf{m}}^{\prime} \mathbf{1}_{\mathbf{J}}$ & 0 & 12,810 & 23,238 & 24,407 \\
\hline$\underline{\mu_{\mathrm{US}} f_{\mathrm{US}}\left(n_{\mathrm{US}}+m_{\mathrm{US}}\right)}, \underline{\mu_{0} f\left(n_{0}-\mathbf{m}^{\prime} \mathbf{1}_{\mathbf{J}}\right)}$ & 707 & 681 & 698 & 698 \\
\hline$n_{0}-\mathbf{m}^{\prime} \mathbf{1}_{\mathbf{J}}$ & & & & \\
\hline
\end{tabular}

Finally, there is a big difference between the gains if all high-income OECD countries are involved compared to the situation where only the G7 countries participated in the treaty. 
By enlarging the pool of participating countries, we make the externalities stronger, which translates into a bigger difference between no-regret and nationalist allocations. However, enlarging the pool of rich countries further, to include non-OECD high income countries, does not bring many additional gains.

\subsection{Decentralization (with $\beta_{0}$ )}

We then computed the vectors of subsidies $\overline{\mathbf{p}}$ and lump-sum taxes $\overline{\mathbf{q}}$ that would make the noregret allocation incentive compatible (Proposition 5 ). Table 5 gives the result. The subsidies $p_{j}$ are computed for $1,000,000$ additional migrants and expressed in USD per citizen. ${ }^{9} \mathrm{We}$ first observe that households in small countries receive more per migrant than households in large countries. Indeed, welcoming 1,000 additional migrants is much more significant in Luxembourg than in the US. To a lower extent, the subsidy per migrant increases with the level of productivity: citizens from richer countries require higher subsidies to welcome additional migrants. Finally, we also observe that subsidies are larger when the set of countries participating in the arrangement is larger. This occurs because the size of the positive externality increases with the size of the set of participating countries.

To evaluate whether our scheme implies a reasonable initial contribution to the global migration fund, Table 6 presents the ratio

$$
\frac{q_{j}-p_{j} \tilde{m}_{j}}{\mu_{j} f\left(n_{j}+\tilde{m}_{j}\right)}=\frac{p_{j}\left(\bar{m}_{j}-\tilde{m}_{j}\right)}{\mu_{j} f\left(n_{j}+\tilde{m}_{j}\right)}
$$

which expresses the lump-sum contribution as a percentage of GDP (net of due subsidies for existing migrants), or, equivalently, the total subsidies received for hosting $\bar{m}_{j}-\tilde{m}_{j}$ additional migrants. This contributions varies with the size of the country. In the G7 package, it ranges between 0.17 and 0.26 percent of GDP. In the high-income package, it goes between 0.25 and 0.66 percent of GDP. This is of the same order of magnitude as foreign aid; however, in our case, countries get their contributions back once they have welcomed the targeted number of additional migrants.

\subsection{Robustness analysis}

The number of additional migrants generated by the no-regret allocation depends on the value of the welfare externality, i.e. on the rate of altruism and the effect of migration on income in developing countries. Above, the latter goes only through increasing marginal productivity of labor in developing this section, we evaluate the robustness of our results to the choice of the altruism factor, $\beta$, and to the inclusion of remittances. These two ingredients are susceptible to modify the value of the externality. In particular, remittances

\footnotetext{
${ }^{9}$ The subsidy per citizen should be considered as an annual amount, since all the GDP data we used are annual. If migrants stay on average 30 years in the destination countries and the real interest rate is 3 percent, a subsidy of 3.9 (Australia, OECD package) implies a total discounted subsidy of about 80 dollars per 1,000,000 immigrants for a 30 years residence.
} 
Table 5: Subsidy per citizen $p_{j} / n_{j}$ for $1,000,000$ additional migrants (in USD)

\begin{tabular}{|c|c|c|c|}
\hline \multirow[t]{2}{*}{$\overline{\text { Country }}$} & \multicolumn{2}{|c|}{ No-regret $\left(\beta_{0}\right)$} & \multirow[b]{2}{*}{ High income } \\
\hline & G7 & OECD & \\
\hline Australia & & 3.9 & 4.0 \\
\hline Austria & & 8.5 & 8.7 \\
\hline Bahamas & & & 260.5 \\
\hline Bahrain & & & 238.6 \\
\hline Belgium & & 5.6 & 5.7 \\
\hline Brunei & & & 623.5 \\
\hline Canada & 1.9 & 2.6 & 2.7 \\
\hline Cyprus & & & 75.0 \\
\hline Denmark & & 11.9 & 12.3 \\
\hline Finland & & 9.8 & 10.1 \\
\hline France & 0.7 & 1.0 & 1.1 \\
\hline Germany & 0.5 & 0.7 & 0.7 \\
\hline Greece & & 3.8 & 3.9 \\
\hline Hong Kong & & & 23.4 \\
\hline Iceland & & 281.2 & 290.1 \\
\hline Ireland & & 20.7 & 21.3 \\
\hline Israel & & & 28.9 \\
\hline Italy & 0.5 & 0.8 & 0.8 \\
\hline Japan & 0.3 & 0.4 & 0.4 \\
\hline Korea Rep & & 0.6 & 0.7 \\
\hline Kuwait & & & 85.4 \\
\hline Luxembourg & & 276.4 & 284.7 \\
\hline Macao & & & 142.0 \\
\hline Malta & & & 84.4 \\
\hline Netherlands & & 4.3 & 4.4 \\
\hline New Zealand & & 13.9 & 14.3 \\
\hline Norway & & 15.7 & 16.2 \\
\hline Portugal & & 4.1 & 4.3 \\
\hline Qatar & & & 601.1 \\
\hline Saudi Arabia & & & 7.3 \\
\hline Singapore & & & 20.6 \\
\hline Slovenia & & & 18.3 \\
\hline Spain & & 1.0 & 1.0 \\
\hline Sweden & & 6.5 & 6.7 \\
\hline Switzerland & & 10.4 & 10.7 \\
\hline UAE & & & 137.9 \\
\hline UK & 0.6 & 0.9 & 1.0 \\
\hline USA & 0.2 & 0.3 & 0.3 \\
\hline
\end{tabular}


Table 6: Initial contributions to the migration Fund as \% of GDP

\begin{tabular}{|c|c|c|c|}
\hline \multirow[t]{2}{*}{ Country } & \multicolumn{3}{|c|}{ No-regret $\left(\beta_{0}\right)$} \\
\hline & G7 & OECD & High income \\
\hline Australia & & 0.0045 & 0.0047 \\
\hline Austria & & 0.0045 & 0.0047 \\
\hline Bahamas & & & 0.0049 \\
\hline Bahrain & & & 0.0036 \\
\hline Belgium & & 0.0049 & 0.0052 \\
\hline Brunei & & & 0.0038 \\
\hline Canada & 0.0023 & 0.0043 & 0.0045 \\
\hline Cyprus & & & 0.0056 \\
\hline Denmark & & 0.0051 & 0.0054 \\
\hline Finland & & 0.0057 & 0.0060 \\
\hline France & 0.0022 & 0.0044 & 0.0046 \\
\hline Germany & 0.0022 & 0.0042 & 0.0044 \\
\hline Greece & & 0.0045 & 0.0048 \\
\hline Hong Kong & & & 0.0035 \\
\hline Iceland & & 0.0055 & 0.0057 \\
\hline Ireland & & 0.0056 & 0.0059 \\
\hline Israel & & & 0.0038 \\
\hline Italy & 0.0026 & 0.0050 & 0.0052 \\
\hline Japan & 0.0021 & 0.0042 & 0.0045 \\
\hline Korea Rep & & 0.0046 & 0.0048 \\
\hline Kuwait & & & 0.0034 \\
\hline Luxembourg & & 0.0048 & 0.0051 \\
\hline Macao & & & 0.0052 \\
\hline Malta & & & 0.0066 \\
\hline Netherlands & & 0.0046 & 0.0049 \\
\hline New Zealand & & 0.0049 & 0.0052 \\
\hline Norway & & 0.0051 & 0.0054 \\
\hline Portugal & & 0.0050 & 0.0053 \\
\hline Qatar & & & 0.0025 \\
\hline Saudi Arabia & & & 0.0040 \\
\hline Singapore & & & 0.0044 \\
\hline Slovenia & & & 0.0058 \\
\hline Spain & & 0.0049 & 0.0052 \\
\hline Sweden & & 0.0047 & 0.0050 \\
\hline Switzerland & & 0.0044 & 0.0046 \\
\hline UAE & & & 0.0027 \\
\hline UK & 0.0024 & 0.0046 & 0.0049 \\
\hline USA & 0.0017 & 0.0034 & 0.0036 \\
\hline
\end{tabular}


are quantitatively important at the global level and may well have a stronger impact on developing countries than changes going through labor markets.

Regarding remittances, we assume the each migrant remits a fraction $\theta$ of her $/$ his income to country 0 . The consumption level of those left behind becomes:

$$
c_{0}=\frac{\mu_{0} f\left(l_{0}\right)}{l_{0}}+\theta \sum_{j} \frac{m_{j} c_{j}^{m}}{l_{0}}
$$

The fraction $\theta$ is calibrated so as to match the ratio of remittances to GDP observed in developing countries (i.e. 1.46 percent in 2000) under the nationalist allocation. This leads to $\theta=0.23$. This proportion is in line with recent empirical studies on the determinants of remittances. Bollard et al. (2009) recently combined 14 household surveys on remittances and income, covering 11 countries. The average "remittances/income" ratio obtained for household with no university degree ranges from 2 percent (in the Australian database) to 34 percent (in the Spanish database). Our $\theta$ belongs to this interval. Kangasniemi, Winters, and Commander (2007) showed that more than half of Indian medical doctors working in the UK remit income to their home country, and these transfers represent on average $16 \%$ of remitters' income. For this group of high-skill workers, remittances thus represent about 10 percent of their total income. Our value for $\theta$ is above this proportion, but looks reasonable since low-skill migrants are usually seen as remitting a higher proportion of their income than the highly skilled.

In order to evaluate the effect of the altruism factor $\beta$ on the increase in migration we could obtained by implementing a no-regret allocation we let $\beta$ vary between 0 and the upper bound $\beta_{\max }$ obtained from experimental games. For each value of $\beta$, we recalibrated the $\gamma_{j}$ in such a way that the nationalist allocation matched the observed data. We then computed the new no-regret allocation and the change in total migration compared to the nationalist allocation.

The left panel of Figure 2 reports the result for the G7 group. The relation between the gain in migration and the altruism factor is concave. With $\beta$ as low as 0.007 we have 12.8 million new migrants ( +44 percent), while with $\beta=0.001$, the number of additional migrants would still be 3 million ( +7 percent). Hence, we do not need implausibly large values of $\beta$ for our international agreement to have a significant effect. Including remittances strongly increases the number of additional migrants generated by our no-regret allocation $(+30$ million rather than +12.8 million with $\left.\beta_{0}=0.007\right)$. With remittances, even a small rate of altruism allows important increases in global labor movements without any utility cost for the rich. Moreover, the results depicted on Figure 2 can be considered as a lower bound since official records underestimate the full scale of remittances. Conservatively adding 50 percent to official flows (see World Bank, 2008) would further increase $\theta$ and the effectiveness of our no regret treaty. Hence, when all rich countries are averse to global inequality, albeit to a very small extent, setting up a global migration fund designed to coordinate national immigration policies is likely to generate huge welfare gains for millions of additional migrants and for billions of individuals left in the poor world.

The right panel of Figure 2 shows the average migration subsidy per native as a function of the altruism factor $\beta$. Unlike total additional migration, the relation here is linear. It is 
Figure 2: Sensitivity of the results to the altruism factor
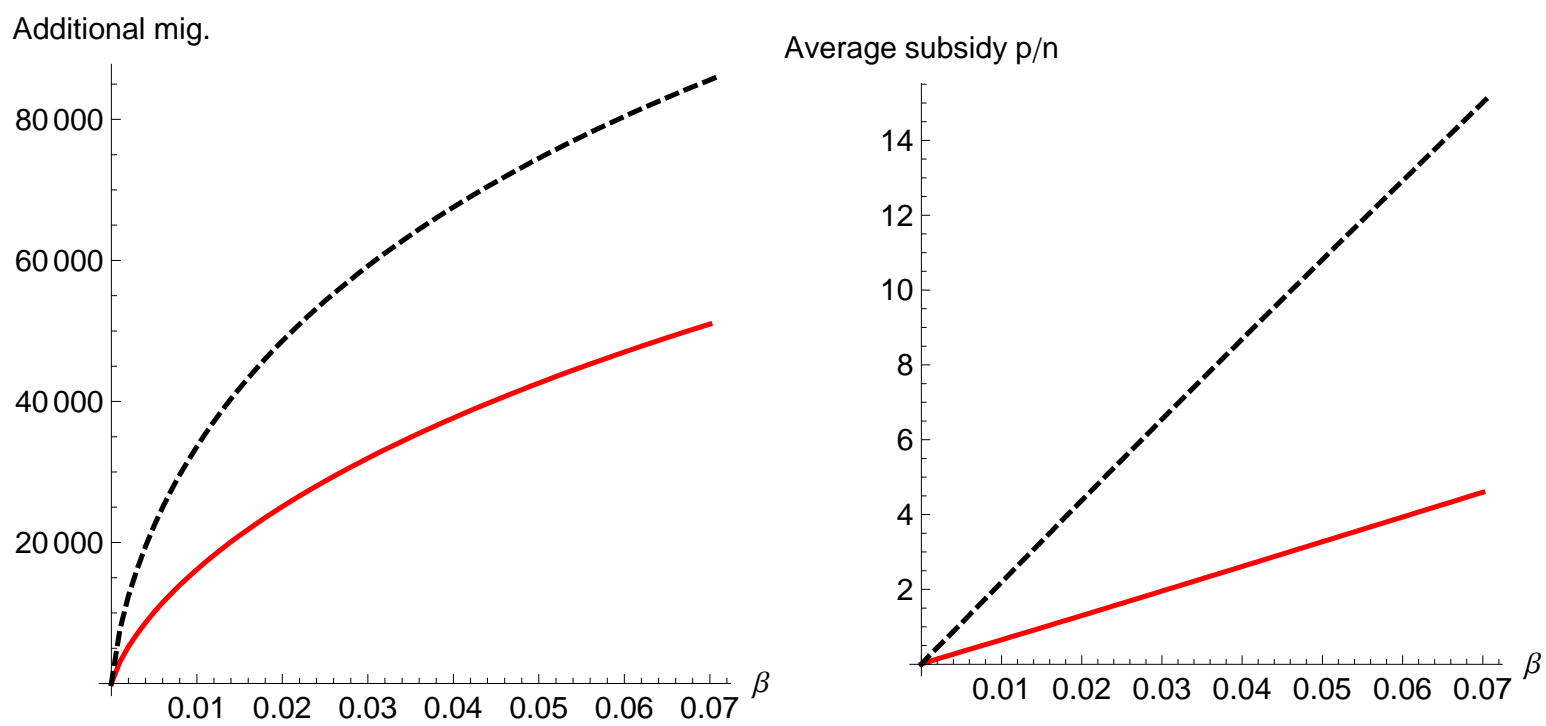

Note: G7 group - solid line: benchmark - dotted line: with remittances

worth noticing that the average subsidy is almost multiplied by four when remittances are factored in.

\section{Conclusion}

Most of the literature on the political economy of migration is written from the point of view of the host country. For example, Benhabib (1996) and Crettez (2007) consider the immigration policy voted for by citizens. These studies give a richer description of what we called above a nationalist policy, with different instruments and heterogeneous citizens, but they do not consider ways to improve upon such policy to increase global welfare. A few papers take the point of view of a benevolent planner maximizing world welfare as for example Benhabib and Jovanovic (2007). They show how the optimal policy depends on technology (constant or decreasing social return, relative backwardness of poor countries, externalities) and on the weight the planner attaches to rich countries. However, they do not care about rich countries' incentives to conduct such an optimal policy.

Our study relies on the fact that political economy mechanisms are essential to understand or influence immigration policies in rich countries. Compared to these two strands of the literature we take a different point of view: maximizing world welfare subject to an implementability constraint, expressing the idea that the rich countries are not ready to accept any loss of welfare. We accordingly proposed a political mechanism that improves the international allocation of labor by considering solutions that are politically acceptable in rich countries. 
Increasing migration and reducing global inequality subject to the implementability constraint is possible provided that households are averse to inequality. Nevertheless, in the absence of any coordinating device, citizen in any given rich country lack incentives to welcome additional migrants as this policy is a global public good, benefitting to all rich countries. We showed that we can construct a "no-regret" allocation taking into account the public good nature of immigration policy better, and that this allocation can be supported by a tax-subsidy scheme.

In order to quantitatively assess the increase in migration that such a no-regret allocation can bring, we calibrated the model using statistics on immigration, working-age population and output. We simulated the proposed scheme on different sets of rich countries. We showed that if altruism is as strong as predicted by experimental games, our policy would produce a very significant increase in global migration; but even for low levels of altruism, the effect of our policy would not be negligible.

\section{References}

Andreoni, James. 2006. "Philanthropy." In Handbook of the Economics of Giving, Altruism and Reciprocity, edited by S.C. Kolm and J. Mercier-Ythier, Volume 2, 1201-1269. Elsevier North-Holland.

Auerbach, Alan J., and Philip Oreopoulos. 1999. "Analyzing the fiscal impact of US immigration." American Economic Review 89:176-180.

Azam, Jean-Paul, and Jean-Jacques Laffont. 2003. "Contracting for aid." Journal of Development Economics 70:25-58.

Bekkers, René. 2007. "Measuring altruistic behavior in surveys: The all or nothing dictator game." Survey Research Methods 1 (3): 139-144.

Benhabib, Jess. 1996. "On the political economy of immigration." European Economic Review 40 (9): 1737-1743 (December).

Benhabib, Jess, and Boyan Jovanovic. 2007, January. "Optimal migration: a world perspective." Working paper 12871, National Bureau of Economic Research.

Boeri, Tito, Gordon H. Hanson, and Barry McCormick. 2002. Immigration Policy and the Welfare State. Oxford: Oxford University Press.

Bollard, Albert, David McKenzie, Melanie Morten, and Hillel Rapoport. 2009. "Remittances and the Brain Drain Revisited: The Microdata Show That More Educated Migrants Remit More?" Working Papers 2009-26, Department of Economics, Bar-Ilan University.

Bonin, Holger, Bernd Raffelhüschen, and Jan Walliser. 2000. "Can immigration alleviate the demographic burden." FinanzArchiv 57 (1): 1-21.

Borjas, George. 1995. "The economic benefits from immigration." Journal of Economic Literature 9 (2): 3-22. 
Bubb, Ryan, Michael Kremer, and David Levine. 2007. "The economics of international refugee law." mimeo.

Burnside, Craig, and David Dollar. 2000. "Aid, Policies, and Growth." American Economic Review 90 (4): 847-868 (September).

Charness, Gary, and Matthew Rabin. 2002. "Understanding social preferences with simple tests." Quarterly Journal of Economics, pp. 817-869.

- 2005. "Expressed preferences and behavior in experimental games." Games and Economic Behavior 53:151-169.

Chojnicki, Xavier. 2006. "Vieillissement démographique et immigration: un modèle de comptabilité générationnelle appliqué à la France." Economie et Prévisions 174 (3): 39-57.

Crettez, Bertrand. 2007. "Is Selling Immigration Rights Politically Sustainable ?" University Paris X.

Docquier, Frédéric, B Lindsay Lowell, and Abdeslam Marfouk. 2009. "A gendered assessment of highly skilled emigration." Population and Development Review, p. forthcoming.

Drinkwater, Stephen, Paul Levine, Emanuela Lotti, and Joseph Pearlman. 2007. "The immigration surplus revisited in a general equilibrium model with endogenous growth." Journal of Regional Science 47 (3): 569-601.

Easterly, William, Ross Levine, and David Roodman. 2003. "New data, new doubts: a comment on Burnside and Dollar's 'Aid, policies and growth (2000)'." Mimeo, Department of Economics, New York University.

Facchini, Giovanni, and Anna Maria Mayda. 2008. "From individual attitudes towards migrants to migration policy outcomes: theory and evidence." Economic Policy 23:651713.

- 2009. "Does the welfare state affect individual attitudes towards immigrants? Evidence across countries." Review of Economics and Statistics 91 (2): 295-314.

Fehr, Ernst, and Klaus M. Schmidt. 2006. "The economics of fairness, reciprocity and altruism: experimental evidence and new theories." In Handbook of the Economics of Giving, Altruism and Reciprocity, edited by S.C. Kolm and J. Mercier-Ythier, Volume 1, 615-691. Elsevier North-Holland.

Gersbach, Hans, and Ralph Winkler. 2007, July. "On the design of global refunding and climate change." Discussion paper 6379, CEPR.

Hansen, Henrik, and Finn Tarp. 2000. "Aid effectiveness disputed." Journal of International Development 12 (3): 375-398.

Hatton, Timothy J. 2004. "Seeking asylum in Europe." Economic Policy, vol. 19.

Hatton, Timothy J., and Jeffrey G. Williamson. 2006. "Refugees, asylum seekers, and policy in Europe." In Labour mobility and the World Economy, edited by Federico Foders and Rolf J. Langhammer, 250-284. Kiel: Springer. 
Kanbur, Ravi. 2006. "The economics of international aid." In Handbook of the Economics of Giving, Altruism and Reciprocity, edited by S.C. Kolm and J. Mercier-Ythier, Volume 2, 1559-1588. Elsevier North-Holland.

Kangasniemi, Mari, L. Alan Winters, and Simon Commander. 2007. "Is the medical brain drain beneficial? Evidence from overseas doctors in the UK." Social Science and Medicine 65:915-923.

Parsons, Christopher R., Ronald Skeldon, Terrie L. Walmsley, and L. Alan Winters. 2007, March. "Quantifying international migration : a database of bilateral migrant stocks." Policy Research Working Paper Series 4165, The World Bank.

Pritchett, Lane. 2006. Let Their People Come: Breaking the Gridlock on Global Labor Mobility. Center for Global Development; University Presses Marketing, distributor.

Rose Skaksen, Jan, Nikolaj Malchow-Møller, and Claus Aastrup Jensen. 2007. "Does Coordination of Immigration Policies among Destination Countries Increase Immigration?" Working paper 2007-15, Copenhagen Business School, Department of Economics.

World Bank, The. 2008. World Development Indicators. Washington DC: World Bank.

Yaari, Menahem, and Maya Bar-Hillel. 1984. "On dividing justly." Social Choice and Welfare, vol. I. 